\title{
The Impact of Ageing Population on Malaysian Economic Growth
}

\author{
Mazlynda Md Yusuf ${ }^{1^{*}}$, Sarina Mohamed ${ }^{1}$, Mohamad Yazis Ali Basah ${ }^{2}$ \\ ${ }^{1}$ Faculty of Science and Technology, Universiti Sains Islam Malaysia (USIM), \\ 71800, Bandar Baru Nilai, Nilai, Negeri Sembilan, Malaysia \\ ${ }^{2}$ Faculty of Economics and Muamalat, Universiti Sains Islam Malaysia (USIM), \\ 71800, Bandar Baru Nilai, Nilai, Negeri Sembilan, Malaysia
}

\begin{abstract}
An ageing population is a worldwide phenomenon, as the results of improvement in mortality rates and drops in fertility rate over the past century. Previously, this trend was focused among the developed countries of Europe and North America but over the past 20 years, the ageing population has started to grow in the developing countries, especially countries of Southeast Asia such as Malaysia. Given changes in fertility and improving life expectancy, the figure is expected to increase significantly. According to the Department of Statistics Malaysia, it is estimated that $6.5 \%$ of the total population is aged 65 and above in 2018 and this figure is expected to increase to 14.5\% in 2040. With the current changes in the demographic trend, it is expected that there will be changes in the amount of savings and this could also lead to changes in the economic performances in the future. Thus, the main objective of this study is to examine the impact of the ageing population on economic growth in Malaysia by using annual data from the year 1985 to 2016. Total fertility rates, life expectancy, labour force participation rate and old-dependency ratio are variables that are used in the study. These data were analysed using Multiple Linear Regression Model and the results indicate that Malaysia is expected to experience the ageing population in the future and that it gives effect towards Malaysian's economic growth.
\end{abstract}

Keywords: ageing population; economic growth; life expectancy; labour force participation; olddependency ratio; fertility rates

\section{INTRODUCTION}

United Nations (2017) has reported that Asian countries will face the ageing population over the coming decades with the percentage increase from $12 \%$ in 2017 to $24 \%$ in the year 2050. Malaysia is no exception. Ageing population can be defined as population of older people in specific country; Malaysia defined as aged 65 and above (Department of Statistics, 2017). According to the Department of Statistics Malaysia (2018), the percentage of old age is expected to increase from $5 \%$ in 2010 to $14.5 \%$ in 2040 and this increase in the ageing population is due to the increase in life expectancy when people are expected to live longer. As at current, the life expectancy rate in Malaysia is 77.6 years old for female and 72.7 years old for a male (Department of Statistics, 2018).

Bloom et. al., (2011) stated that ageing societies contribute to lower saving rates as well as labour-force participation, therefore increasing the worries of slowing economic performances in the future. However, Prettner (2013) stated that the ageing population can also increase the amount of savings in the economy as the older individuals tend to save more to finance their longer lives, thus working longer and potentially provide more capitals for investment that could affect the economic growth. Since Malaysia's population is moving towards the ageing population, therefore, this study attempts to investigate the impact of the current ageing population on Malaysian economic growth. 


\section{LITERATURE REVIEW}

\section{A. Life Expectancy}

Longevity is usually measured by life expectancy which is the number of years a person is likely to live at a specific time of their life course. However, life expectancy is commonly influenced by the society in which the person lives and by the genetic characteristics with which they are born (Weeks, 2005). The increase in life expectancy is due to improvement in a healthy lifestyle as well as technology. With the declining rates of fertility, infant and adult mortality, and increasing life expectancy, Malaysia is presently facing both an increasing number and proportion of older people that is continuously growing. Other ASEAN countries are also experiencing similar increasing in the ageing population, largely due to increased life expectancy and a lowered fertility rate (ASSA, 2006).

The rising in life expectancy as an indicator for the demographic changes tends to let an individual live longer. In particular, the expectation of living longer than the past generation may increase their desire to stay longer in the labour force and increase the amount of savings in the economy (Mason and Lee, 2006). Moreover, the increase in longevity and ageing population demands that the government and policymakers improve the retirement policy, pension and health care system, the labour efficiency and capital markets as well as the regional structure and global economic systems. Thus, the increase in ageing population alarms the government to emphasize the concerns highlighted in order to improve the economic performances of the country in the future.

A study was done by Futagami and Nakajima (2001) on the impact of the ageing population towards economic growth has concluded that an increase in life expectancy would lead people to save more for future consumption in order to have a comfortable standard of living in later life. This is because the savings is hoped to be able to sustain their living expenses during old age. Therefore, the increase in savings will then accelerate the output growth rate for the country.

Another study by Daron and Simon (2006) on the effect of life expectancy from birth towards the economic growth and has concluded that the increase in life expectancy leads to a reduction of income per capita and slowly improving for the next 40 years. The study by Daron and Simon also shows no evidence that an increase in life expectancy would lead to a significant increase per capita economic growth.

\section{B. Fertility Rates}

Total fertility rate (TFR) is defined as the average number of children born or likely to be born to a woman in a lifetime adjusting to the age-specific fertility rates of a given year in the population (WHO, 2018). In 2018, the Department of Statistics Malaysia has reported that the total fertility rates have declined from 2.9 in the year 2000 to 1.9 in the year 2017. Even though there is a reduction in the number of children given birth by each woman, it does not reduce the number of populations in the country due to the increase in life expectancy. Therefore, the demographic trend shows a decrease in the younger-age group, but a significant increase in the old-age group as they are expected to live longer. Thus, with the increasing number of older people in the country, would it affect the country's economy?

Quamrul et. al., (2013) have studied the effect of fertility reduction on economic growth using data from Nigeria and have found that declining fertility rates increase the output per capita. This result is also agreed by Normaz et. al., (2015) and Yujie Li (2015), on the research of how fertility rates affect economic growth. These studies have revealed that the reduction of fertility rate led to higher economic growth and this shows that even though the country's fertility rates reduce, it could still lead to an increase in the economic growth rate (Prettner, 2013).

Apart from that, a reduction in total fertility rates tends to have a significant effect on the increase in female labour force participation (Bloom et. al., 2009). Their finding has shown that a decline in total fertility rate by reducing one child will increase the labour force participation rate for four years. Thus, a decline in fertility rates contributes to the rising in working-age share and decreases the youth-age population share in the short run since women are expected to stay longer in the workforce once they have fewer children. Therefore, the increase of the working-age population gives benefit to the country as it will increase the productivity of the country, hence the economic performances are improved.

\section{Labour Force Participation}

Due to improved longevity, it is claimed that living longer means older men and women can continue working and 
contributing to economic and social development. United Nations (2018) has reported that the ageing population not only results in significant implications towards family structures and demand for goods and services but also towards labour and financial markets. According to Maestas et. al., (2016), ageing societies is projected to give negative consequences on economic growth. Based on their study, a $10 \%$ rise in the fragment of the population age 60 or elder declines the growth rate in GDP per capita by $5.7 \%$. The findings also show that the decline in labour force participation and labour productivity is due to the rise in the ageing population and then slow down economic growth.

The ageing population is described to have an impact on economic growth through three main mechanisms: public expenses, consumption and saving structure as well as human capital (Nagarajan et. al., 2016). The findings demonstrate that $70 \%$ of the empirical studies show that the public social expenses have a negative relationship with the ageing population and economic performances and $60 \%$ of the empirical studies show that the human capital does not have a significant relationship between the ageing population and economic growth. The results indicate that public expenses and human capital does not affect the growth of the economy even with the increasing number of ageing populations.

A study by Muhammad Shahid (2014) on the impact of labour force participation towards economic growth in Pakistan using Augmented Dicky Fuller and Phillip Perron tests has resulted that the labour force participation has a negative relationship on economic growth. On the other hand, Jan Cadil et. al., (2014) has concluded that there is a positive effect of human capital on the economic growth in the EU regions only in the group of big cities.

Since women are expected to live longer due to the increase in life expectancy, Majlinda and Jeton (2015) have studied on the effect of the female labour force in economic growth for South Eastern European countries using STATA program. The analysis has shown that the economic growth and government effectiveness has a negative impact on the female labour force and that female labour force is negatively correlated with the economic growth and financial development market. Hence, this shows that even though women are expected to stay in the labour force longer, they do not contribute to the growth of the economy for the country.

\section{Old-Dependency Ratio}

According to the United Nation (2015), one of the factors behind the ageing population is related to the old-age dependency ratio. Over the long run, if the fertility rates of the country continue to decline, the working age population would also decline and this results to an increase in the ageing population, leading to rising of the dependency ratio (WHO, 2018). Dependency ratio can be defined as the population in the age groups of young and old age to be bear for every 100 people of working age. The increase in the total dependency ratio from 47.8 in 2010 to 49.5 in 2040 is due to an increase in the old age dependency ratio, almost a three-fold increase from 7.4 in 2010 to 21.7 in 2040 (DOS, 2018). The figure shows that the portion of old- age is increasing for every 100 people of the working age.

Research by Heinrich and Weil (2006) investigated how an ageing population in the country interacts with fertility and economic dependency. The study used a time generation's model and divided the population into three groups which are young (group of young people who have never worked), working age (group of people in the economy that are still working) and old (group of people that has once worked and are now retired). Based on their study, Heinrich and Weil argued that a large fraction of a working-age population's income will be given to the elderly generation if a specific country has a high level of old-age dependency ratio.

According to a study by E.H. Flores (2015) that investigates on the impact of population decline on Japanese economic performance, Japan has gained benefit from a lower dependency ratio during the fast industrialization period in 1970. However, the rapidly ageing society in Japan has projected in an increasing dependency ratio, 0.65 in 2015 to just about 1.0 in 2050. The findings showed that the population dynamics give a negative impact on economic growth in Japan up until 2050.

Another study by Bloom et. al., (2011), the youth and old age dependency ratio give the impact on the growth of income per capita negatively in the short run. However, the result of the study has revealed that once the population age distribution has become stabilized, the higher young age dependency still impacts the economic growth negatively on the long run compared to the old-age dependency ratio. The difference between the young-age dependency ratio and oldage dependency ratio is due to the greater capacity for the economies to adapt to the changes of the elderly population than the changes in the younger population. Thus, the 
findings concluded that high old-age dependency ratio may not have a significant effect on the income per capita in the long run. This result is also supported by Ana Maria Santacreu (2016) that indicates the increase in the ageing population could lead to slower down the economic growth.

\section{METHODOLOGY}

The impact of ageing populations on economic growth in Malaysia in this study were analysed using Multiple Linear Regression (MLR) model with the method of ordinary least square (OLS) in EVIEWS. The data collected from 1985 to 2016 is obtained from the Department of Statistic Malaysia and The World Bank. The dependent variable for the study is the growth domestic product in Malaysia representing the economic growth in Malaysia. The independent variables are total fertility rates, life expectancy, old- dependency ratio and labour force participation for male and female.

Before proceeding with the analysis, few assumptions were used for data checking purposes. Extreme figures were checked to avoid any outliers in the data. Multicollinearity test were also performed among the independent variables to show that at least there are some relationship with the dependent variable. Then Multiple Linear Regression analysis is performed.

Multiple Linear Regression model considers the relationship between the dependent variable, which is denoted by $y$ and the independent variable is denoted by $x$. The regression model for this study can be built as follows:

$$
\log Y=\beta_{0}+\beta_{1} X_{1}+\beta_{2} X_{2}+\beta_{3} X_{3}+\beta_{4} X_{4}+\varepsilon
$$

where,

$Y=$ Gross Domestic Product

$X_{1}=$ Total fertility rates

$X_{2}=$ Life Expectancy

$X_{3}=$ Old- Dependency Ratio

$X_{4}=$ Labour Force Participation Rate

$\varepsilon=$ Error (the disturbance term)

$\beta_{i}=$ parameters $i=0,1,2,3$ and 4

The results from this model detail the correlation between independent variables (total fertility rates, life expectancy, old-dependency ratio, labour force participation rate) with the dependent variable (Gross Domestic Product). Since the value of GDP per capita is a large number, hence this study implements log-level regression in order to impose a constant percentage effect of all variables towards GDP. The coefficient from $\beta_{1}$ to $\beta_{4}$ determines the changes between the variables towards economic growth and any unexplained variation that is captured by the random error" $\varepsilon "$.

\section{RESULTS AND DISCUSSIONS}

Table 1 below summarizes the results of all the determinants towards GDP as well as the impact towards an ageing population. The coefficients measure the changes of one determinant, holding all other factors fixed.

The coefficient of life expectancy explained that if life expectancy is increased by a year, the growth domestic product will increase by $20.85 \%$. The increase in life expectancy has been affected by an improvement in health facilities and good control of infectious disease. Mahumud et. al., (2013) also observed that in his study, a positive relationship between economic growths measured in per capita GDP with life expectancy due to three factors. Firstly, when individuals are in good health condition, their income will increase as they turn to be productive and physically more energetic. Secondly, individuals start to improve their economic development by increasing their savings. Since people tend to live longer, they tend to invest more for retirement. The third factor is the development in health status; thus, this will increase the economic growth of their country through the development in the education levels.

Table 1. Regression results of proxies for an ageing population with GDP as the dependent variable for economic growth.

\begin{tabular}{|c|c|c|c|}
\hline Predictor & Coef & $\mathrm{t}$ & Sig. \\
\hline Life expectancy & 0.2085 & 2.9619 & 0.0068 \\
\hline $\begin{array}{c}\text { Old - } \\
\text { dependency ratio }\end{array}$ & 0.3378 & 2.5172 & 0.0189 \\
\hline $\begin{array}{c}\text { Total fertility } \\
\text { rates }\end{array}$ & -0.2819 & -1.2720 & 0.2156 \\
\hline $\begin{array}{l}\text { Labour force } \\
\text { participation }\end{array}$ & 0.000475 & 0.385908 & 0.7028 \\
\hline$R^{2}$ & 0.9877 & & \\
\hline
\end{tabular}

Apart from that, the old-dependency ratio also resulted in a positive relationship with the economic growth in Malaysia. The coefficient of old- dependency ratio means that when the old dependency ratio increases by 1 unit, the GDP per capita is expected to increase about $33.78 \%$. When the ratio of the 
number of elderlies per working-age population is getting bigger, the population aged 65 and above is higher than the population aged 15 until 45. Thus, the number of elderly populations increases, and the number of pensioners will also be parallel. The elderly populations should increase their saving through a pension plan or healthcare insurance as they are reaching upon their retirement age. Futagami and Nakajima (2001) mentioned that individuals tend to consume less and increase their savings in order to have a contented standard of living in later life. Increased savings will then accelerate the output growth of the country. However, if the old dependency ratio decreases, more working populations needed to increase labour productivity. Due to this, the working populations need to support the elderly population in order to sustain the performance in the economic growth of the country.

On the other hand, the results show that the coefficient for the total fertility rate has a negative impact on economic growth. Declining in 1 unit of fertility rate will cause GDP per capita to increase by $28.19 \%$. The $t$-statistics for total fertility rate is -1.27 and the $p$-value of total fertility rate are 0.2156 . The result shows that any changes in total fertility rates are insignificant in affecting economic growth. The results are also parallel with a study by Sindig (2007) that highlighted with a reduction in fertility would not, by itself contribute significantly to economic growth. Quamrul et. al., (2013) also analysed how fertility rate affected GDP by using pragmatic and quantitative lines and according to the simulation, a reduction of fertility rate could be economically significant, but it only gives a relatively small effect towards the economic growth. Labour force participation rates show no significant effect on the economic growth with the p-value resulted at 0.7028. Hence, this shows that economic growth in Malaysia is yet to be influenced by the current labour force participation rate.

\section{CONCLUSION}

The focus of this study is to investigate the impact of the ageing population on Malaysian economic growth. Since Malaysia is moving towards the ageing population, therefore it is important to investigate the impact of the ageing population on economic growth. The analysis is carried out by using Multiple Linear Regression Model Approach for the period of 1985 to 2016. In this study, the relationship between the dependent variable which is the economic growth and the independent variables; life expectancy, total fertility rates and old- age dependency ratios are used as proxies for the ageing population. In conclusion, Malaysian total fertility rates and labour force participation rates do not show a significant impact on economic growth.

However, the other two factors; life expectancy and olddependency ratios show a positive relationship with economic growth. Therefore, the study is recommended to be repeated again in the next 30 years to investigate if there are any significant changes in the results when the ageing population increases to a higher ratio. This is because Malaysia is expected to be categorized as an ageing country by 2050 .

\section{REFERENCES}

Ana Maria Santacreu 2016, "Long Run Economic Effects of Changes in the Age Dependency Ratio", Economic Research, No 17

ASSA. 2006 "Demographic Changes and Challenges in ASEAN Countries". ASSA Board Meeting Seminar: Implications of Ageing Population. Penang, Malaysia.

Bloom, David E and J E Finlay 2009. "Demographic change and economic growth in Asia", Asian Economic Policy Review, 4: 45-64

Bloom, D. E, Canning, D., \& Fink, G. 2011, "Implications of Population Ageing for Economic Growth”. National Bureau of Economic Research Working Paper Series. Retrieved from http://www.nber.org/papers/w16705.pdf
Daron, A \& Simon, J. 2006. "Disease and Development: The Effect of Life Expectancy on Economic Growth". National Bureau of Economic Research Working Paper Series. Retrieved fromhttp://www.nber.org/papers/w12269.pdf Department of Statistics 2017, Population and Demography of Malaysia. Ageing Newsletter. August. 2017

Department of Statistics 2018, Population and Demography of Malaysia. Population Projection (Revised), 201O-204O. Malaysia.

Flores, Edson H., "Land of the Ageing Sun: The Impact of Population Decline on Japanese Economic Performance" 2015, CUNY Academic Works. http://academicworks.cuny.edu/bb_etds/20 
Futagami, K., \& Nakajima, T. 2001, "Population Ageing and Economic Growth”. Journal of Macroeconomics, 1(23), 3144.

Heinrich, Hock \& Weil, David N. 2006, "The Dynamics of the Age Structure, Dependency and Consumption”, NBER Working Paper No. 12140, National Bureau of Economic Research.

Čadil, J., Petkovová, L., \& Blatná, D. 2014, "Human Capital, Economic Structure and Growth”, Procedia Economics and Finance. Vol (12).85-92.

Maestas, N., Mullen, K., \& Powell, D. 2016, "The Effect of Population Ageing on Economic Growth, the Labour Force and Productivity”. National Bureau of Economic Research Working Paper Series. Retrieved from http://www.nber.org/papers/w22452.pdf

Mahumud, R. A., Hossain, G., Hossain, R., Islam, N., \& Rawal, L. 2013, "Impact of Life Expectancy on Economics Growth and Health Care Expenditures in Bangladesh". Universal Journal of Public Health, 1(4), 180-186.

Majlinda, M., \& Jeton, Z. 2015. "The Effect of Female Labour Force in Economic Growth and Sustainability in Transition Economies - Case Study for SEE Countries”. American Journal of Business, Administration, Law and Social Sciences. Vol (1). No. (2). 179-184.

Mason, A and R Lee 2006, "Reform and support systems for the elderly in developing countries: Capturing the second demographic dividend”, Genus, LXII (2), 11-35.

Muhammad, S. 2014, "Impact of Labour Force Participation on Economic Growth in Pakistan”. Journal of Economics and Sustainable Development. Vol (5). No. (11).

Nagarajan, R., Teixeira, A.A.C. and Silva, S. 2016, "The Impact Of Ageing Population On Economic Growth: An Exploratory Review Of The Main Mechanisms", forthcoming, FEP Working Paper, Faculdade de Economia da Universidade do Porto.

Normaz, W.I., SitiWardah, A.R., \&TengkuAizan, T.A.H. 2015. Does population ageing effect economic growth in Malaysia? Prosiding Persidangan Kebangsaan Ekonomi Malaysia ke-10 (PERKEM 10), 205-210

Prettner, Klaus. 2013, "Population Ageing and Endogenous Economic Growth”. Journal of Population Economics.(26), 811-834

Quamrul, H. A., David, N.W., \& Joshua., W. (2013). "The effect of fertility reduction on economic growth". Population and development review, 39(1), 97-130.

Sindig Steven W. Population, 2009, "Poverty and economic development”. Philosophical Transactions of the Royal
Society B. 2009;364(1532):3023-3030.

United Nations 2017, Department of Economic and Social Affairs, Population Division (2018). World Population Prospects: The 2017 Revision. New York: United Nations.

Weeks, J. R. 2005, "Population: An Introduction to Concepts and Issues", Belmont, CA Thomson Wadsworth Learning. WHO 2018, World Health Organization: Total Fertility Rates. Available:http://www.searo.who.int/entity/health_situati on_trends/data/chi/TFR/en/

WHO 2018, World Health Organization: Elderly Population. Available:http://www.searo.who.int/entity/health situati on trends/data/chi/elderly-population/en/

Yujie, Lee 2015, "The Relationship between Fertility Rate and Economic Growth in Developing Countries". Masters Thesis. Lund University. 